\title{
The Development of Orange Pigment Overlying Choroidal Metastasis
}

\author{
Aline Isabel Riechardt ${ }^{a} \quad$ Enken Gundlach ${ }^{a} \quad$ Antonia M. Joussen ${ }^{a}$ \\ Gregor D. Willerding ${ }^{a}$ b \\ a Department of Ophthalmology, Charité Universitätsmedizin, and \\ ${ }^{b}$ Klinik für Augenheilkunde, DRK Kliniken Westend, Berlin, Germany
}

\section{Key Words}

Choroidal metastasis · Orange pigment $\cdot$ Choroidal melanoma

\begin{abstract}
Aims: The aim of this study was to correlate the ophthalmoscopic and histopathological findings of orange pigment overlying a choroidal metastasis. Methods: This is a single case report with clinical follow-up and histopathological examination. Results: Histopathology revealed a choroidal metastasis with subretinal CD68-positive macrophages showing autofluorescent deposits in fluorescence microscopy. Conclusion: The development of orange pigment is not pathognomonic for choroidal melanoma but may be seen in other lesions such as carcinoma metastasis.

(C) 2015 S. Karger AG, Basel
\end{abstract}

\section{Case Report}

A 73-year-old patient presented with a several-week history of visual impairment in her right eye. The best-corrected visual acuity was 20/32. A left and right mastectomy was carried out 11 and 10 years earlier, respectively, due to invasive ductal carcinoma, which was followed by 5 years of adjuvant treatment with tamoxifen. Three months before presentation, she was diagnosed with pulmonary and osseous metastasis, and systemic therapy with trastuzumab, docetaxel and pamidronate was started.

Ophthalmoscopy revealed a para-macular, amelanotic choroidal tumour associated with sub-retinal fluid (fig. 1). Ultrasound revealed a lesion with a thickness of $4.5 \mathrm{~mm}$, a basal dimension of $12 \times 10 \mathrm{~mm}$ and a medium internal reflectivity in A-scan mode. Fluorescein angiography and fundus autofluorescence were not performed. Choroidal metastasis was diagnosed, and systemic treatment was continued. Six months later, tumour thickness had decreased to $2.0 \mathrm{~mm}$, with resorbed sub-retinal fluid and stable visual acuity. Systemic therapy was adjusted to trastuzumab, anastrozole and pamidronate. Ophthalmic follow-up was provided by the local ophthalmologist. 
Ocular Oncology and Pathology

\begin{tabular}{l|l}
\hline Ocul Oncol Pathol 2015;1:93-97 \\
\hline DOI: 10.1159/000369823 & $\begin{array}{l}\text { ( 2)15 S. Karger AG, Basel } \\
\text { www.karger.com/oop }\end{array}$ \\
\hline
\end{tabular}

Riechardt et al.: The Development of Orange Pigment Overlying Choroidal Metastasis
Fig. 1. Funduscopy at first presentation shows a para-central amelanotic choroidal tumour.

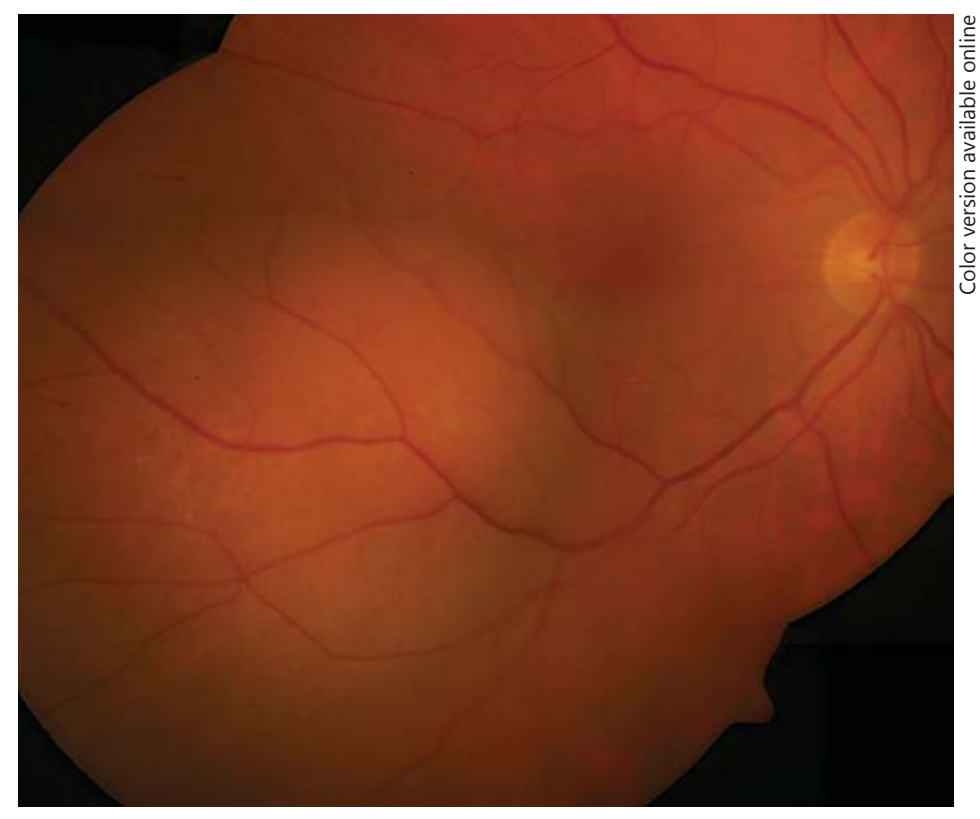

Fig. 2. Nineteen months after the first presentation there is a development of sub-retinal orange pigment.

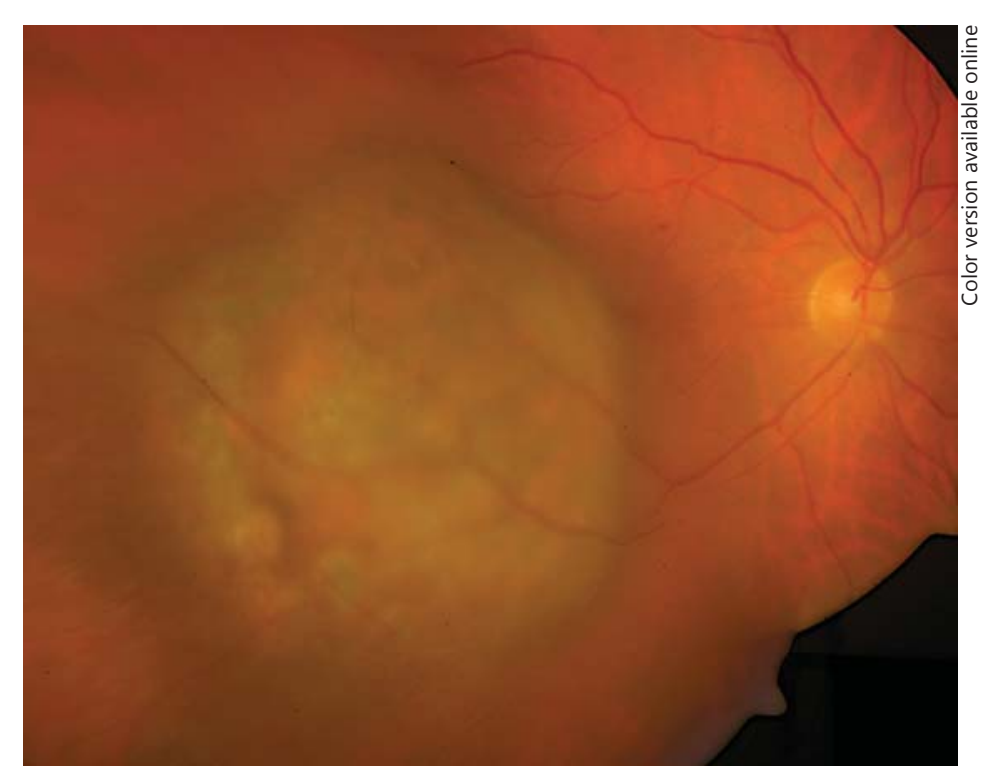

Two years later, the patient presented with a visual deterioration to 20/20. Clinically, the tumour showed distinct growth (tumour thickness $4.9 \mathrm{~mm}$ by ultrasonography), recurrent exudative retinal detachment and abundant orange pigment on the surface (fig. 2). Re-staging was recommended, but the patient did not undergo further evaluation and returned after 6 months with an advanced visual deterioration to counting fingers. Vitreous haemorrhage was noted, and Bruch's membrane rupture was suspected by funduscopy. Tumour thickness was $7.4 \mathrm{~mm}$, and the tumour base measured $15 \times 20 \mathrm{~mm}$, with medium internal reflectivity in A-scan mode. Given the development of orange pigment and suspected Bruch's membrane rupture, choroidal melanoma was considered in the differential diagnosis. Enucleation was performed, and histopathology revealed a choroidal metastasis from breast carcinoma with ductal and papillary differentiation and angioinvasion (fig. 3). The tumour cells showed a strong immunoreactivity for the pan-cytokeratin marker MNF116, and 5-10\% of them were MiB-1 positive. The tumour cells were S100 and Melan-A negative. Her2 was classified as score 2. The tumour cells showed a strong expression for 


\section{Ocular Oncology} and Pathology

Fig. 3. Histopathological section of the enucleated globe showing a dome-shaped choroidal tumour with abundant haemorrhage (asterisk), a fibrotic pseudocapsule and surrounding retinal detachment. The neoplastic cells exhibit a ductal and papillary growth. Cystoid degeneration is present in the retina adherent to the mass. HE. $\times 5$.

Fig. 4. An accumulation of macrophages is present beneath the retina (arrow). These cells are packed with lipofuscin and pigment. Tumour cell sheets are present in the underlying choroid as well as in the sub-retinal space (asterisk), indicating an invasion of the Bruch's membrane elsewhere. Photoreceptor degeneration and RPE layer disruption are also present. HE. $\times 100$.

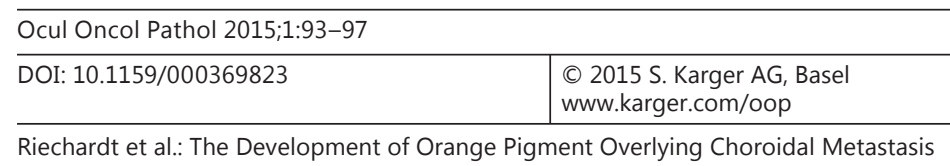

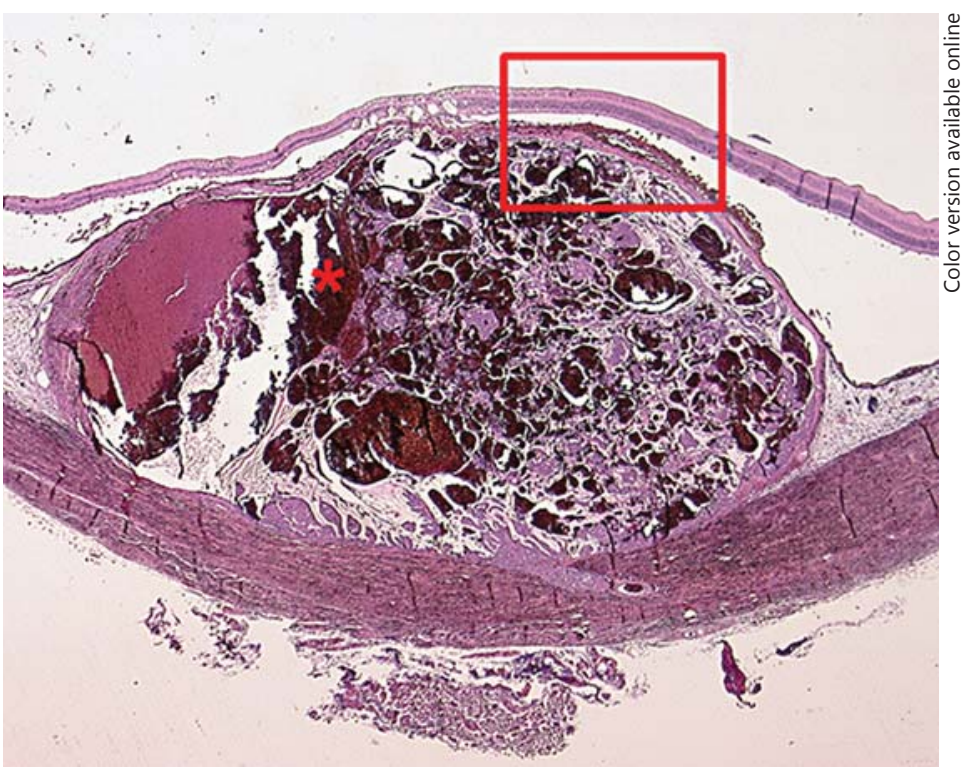

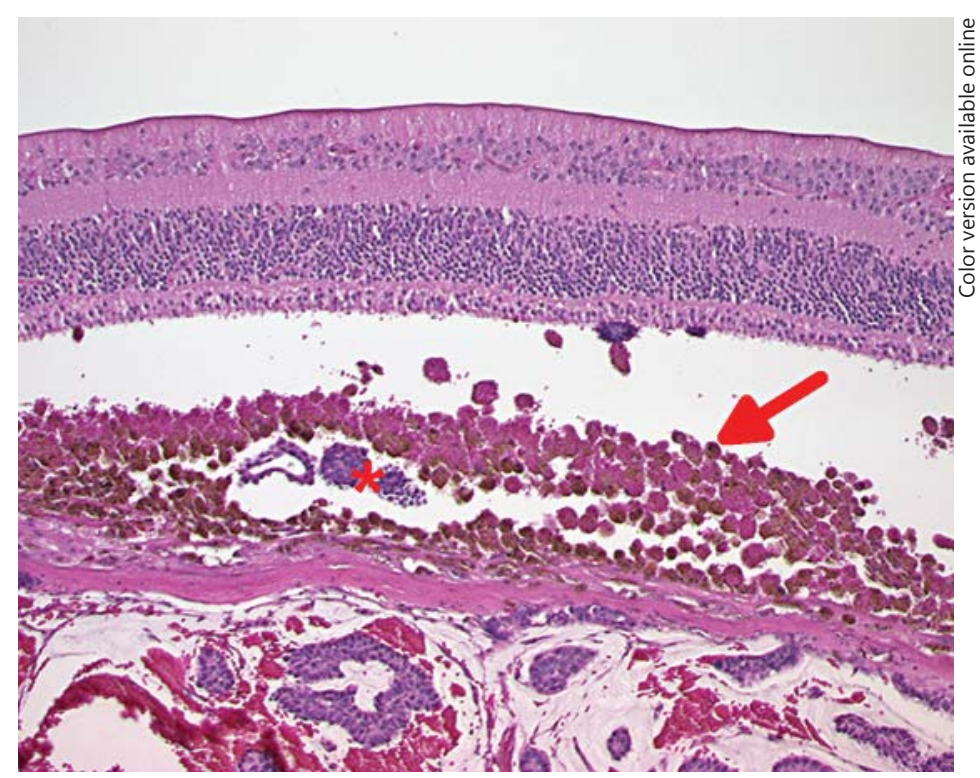

estrogen receptor, but not for progesterone receptor (data not shown). An accumulation of tumour cells and CD68-positive cells could be found sub-retinally (fig. 4, 5). Fluorescence microscopy showed hyperfluorescent deposits within the retinal pigment epithelium (RPE) and the macrophages overlying the tumour (fig. 6).

\section{Discussion}

Metastasis to the choroid is the most common intraocular malignancy. Leading primary sites are breast and bronchial carcinomas [1]. Symptomatic intraocular metastasis might occur as the first sign of dissemination; however, more commonly, patients already have a 
Ocular Oncology

and Pathology

Fig. 5. CD68-positive cells in the sub-retinal space overlying the tumour. $\times 100$.

Fig. 6. Fluorescence microscopy (excitation: $549 \mathrm{~nm}$; emission: $562 \mathrm{~nm}$ ). Autofluorescent deposits within the RPE and the macrophages overlying the tumour. Unstained formalin-fixed paraffinembedded section. $\times 100$.
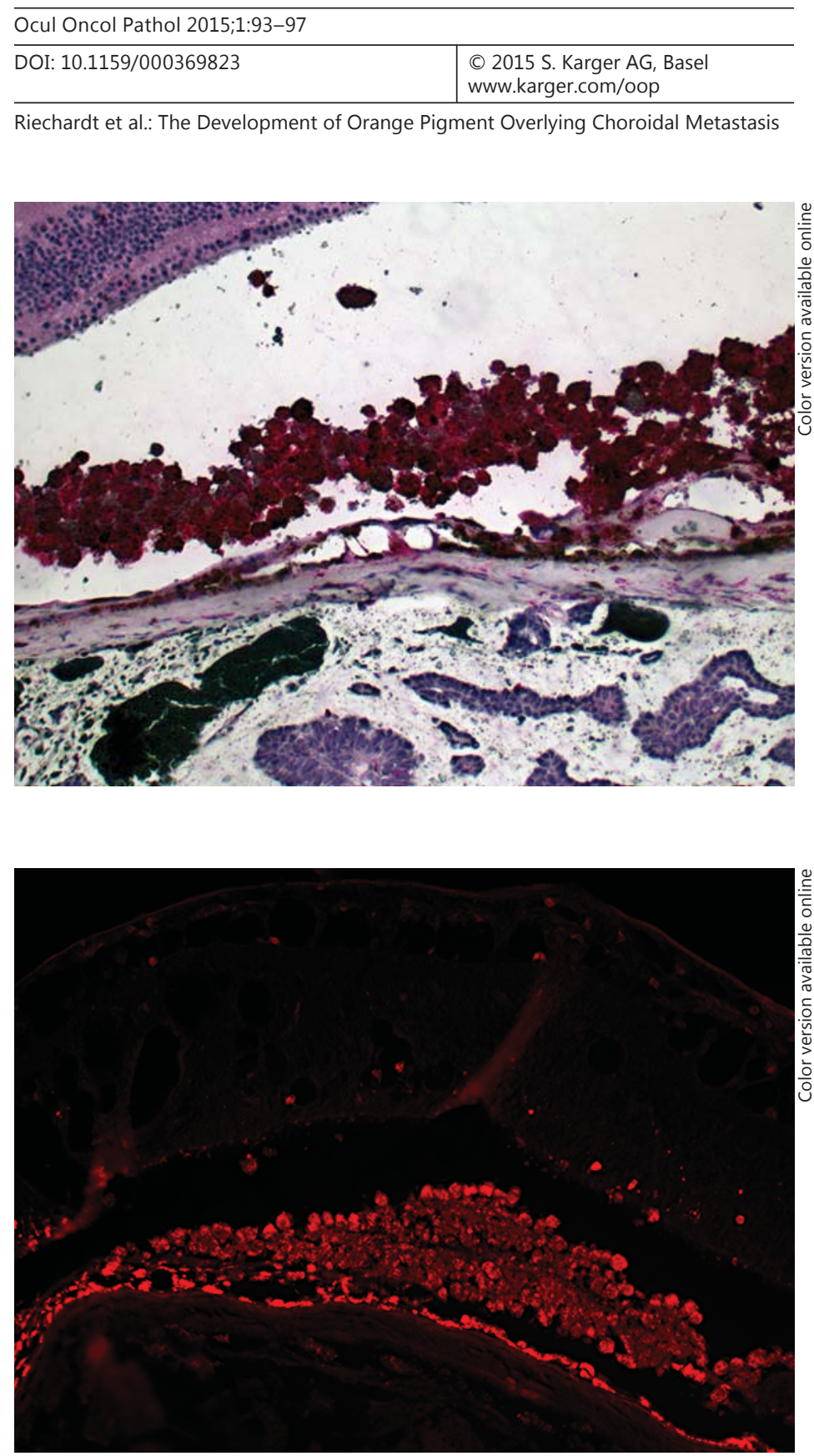

history of involvement of other sites [2-4]. Ocular metastasis is predominantly located in the choroid and less often in the ciliary body and iris, and it is very rare in the retina $[3,5]$. Bilateral or multifocal manifestations are present in up to 38\% [5].

In ultrasonography, choroidal metastases appear variable but tend to show a higher internal reflectivity than melanomas [6,7]. Bruch's membrane rupture can lead to a mushroom shape on ophthalmoscopy and ultrasonography and is highly suggestive, but not pathognomonic, for a choroidal melanoma. Shields et al. [8] and Read et al. [9] both reported on a mushroom-shaped choroidal metastasis. In our case, Bruch's membrane rupture was indicated by the finding of sub-retinal tumour cells.

Orange pigment is an ophthalmoscopic phenomenon representing a sub-retinal accumulation of lipofuscin-laden macrophages on a histopathological level [10]. Lipofuscin is an autofluorescent membrane-bound intracellular material consisting of different fluorophores [11]. Besides the eye, lipofuscin also appears in other organs, such as the brain [12]. In the eye, lipo- 
fuscin is a regular component of the RPE. It is supposed to derive in part from incomplete proteolysis of photoreceptor outer segments [13]. Choroidal tumours are commonly associated with a tumour-associated retinal pigment epitheliopathy [14]. Alteration of the RPE due to subretinal fluid or tumour necrosis can result in the accumulation of lipofuscin in macrophages.

Orange pigment is very characteristic for malignant melanoma of the posterior fundus, but it has also been described overlying choroidal nevi and, rarely, choroidal haemangioma and choroidal metastasis [15]. Choroidal melanoma tends to have a more delayed clinical progression than choroidal metastasis, probably facilitating the formation of orange pigment. In our case of choroidal metastasis, which was incompletely controlled by systemic chemotherapy, orange pigment was noted a significant time of 2.5 years after the initial presentation, when no orange pigment had been noted on clinical examination.

We were able to demonstrate abundant CD68-positive cells in the sub-retinal space corresponding to the clinically evident orange pigment. These cells contained autofluorescent material and resembled macrophages. However, proliferated RPE might contribute to this finding, since it has been shown that RPE can undergo transdifferentiation to a CD68-positive immunophenotype [16]. Ishida et al. [17] described the finding of confluent hyperautofluorescent areas overlying a completely regressed choroidal metastasis from breast cancer after chemotherapy and irradiation without histopathological demonstration.

In conclusion, this case emphasizes that the development of orange pigment is not pathognomonic for choroidal melanoma but may be seen in other lesions such as carcinoma metastasis.

\section{References}

1 Weiss L: Analysis of the incidence of intraocular metastasis. Br J Ophthalmol 1993;77:149-151.

-2 Kreusel KM, Bornfeld N, Hosten N, Wiegel T, Foerster MH: Solitary choroidal metastasis as the first sign of metastatic lung carcinoid. Arch Ophthalmol 1998;116:1396-1397.

- 3 Kreusel KM, Wiegel T, Stange M, Bornfeld N, Foerster MH: Intraocular metastases of metastatic breast carcinoma in the woman. Incidence, risk factors and therapy (in German). Ophthalmologe 2000;97:342-346.

-4 Wiegel T, Kreusel KM, Bornfeld N, Bottke D, Stange M, Foerster M, Hinkelbein W: Frequency of asymptomatic choroidal metastasis in patients with disseminated breast cancer: results of a prospective screening program. Br J Ophthalmol 1998;82:1159-1161.

5 Demirci H, Shields CL, Chao AN, Shields JA: Uveal metastasis from breast cancer in 264 patients. Am J Ophthalmol 2003;136:264-271.

6 Kreusel KM, Bechrakis N, Wiegel T, Emmerlich T, Foerster MH: Clinical characteristics of choroidal metastasis (in German). Ophthalmologe 2003;100:618-622.

7 Sobottka B, Schlote T, Krumpaszky HG, Kreissig I: Choroidal metastases and choroidal melanomas: comparison of ultrasonographic findings. Br J Ophthalmol 1998;82:159-161.

8 Shields JA, Schields CL, Brown GC, Eagle RC: Mushroom-shaped choroidal metastasis simulating a choroidal melanoma. Retina 2002;22:810-813.

-9 Read RW, Green RL, Rao NA: Metastatic adenocarcinoma with rupture through the Bruch membrane simulating a choroidal melanoma. Am J Ophthalmol 2001;132:943-945.

10 Font RL, Zimmermann LE, Armaly MF: The nature of the orange pigment over a choroidal melanoma. Histochemical and electron microscopical observations. Arch Ophthalmol 1974;91:359-362.

11 Kennedy CJ, Rakoczy E, Constable IJ: Lipofuscin of the retinal pigment epithelium: a review. Eye (Lond) 1995; 9:763-771.

12 Ottis P, Koppe K, Onisko B, Dynin I, Arzberger T, Kretzschmar H, Requena JR, Silva CJ, Huston JP, Korth C: Human and rat brain lipofuscin proteome. Proteomics 2012;12:2445-2454.

13 Katz ML: Incomplete proteolysis may contribute to lipofuscin accumulation in the retinal pigment epithelium. Adv Exp Med Biol 1989;266:109-116.

14 Damato BE, Foulds WS: Tumour-associated retinal pigment epitheliopathy. Eye (Lond) 1990;4:382-387.

15 Shields JA, Rodriques MM, Sarin LK, Tasman WS, Annesley WH Jr: Lipofuscin pigment over benign and malignant choroidal tumors. Trans Sect Ophthalmol Am Acad Ophthalmol Otolaryngol 1976;81:871-881.

-16 Elner SG, Elner VM, Nielsen JC, Torczynski E, Yu R, Franklin WA: CD68 antigen expression by human retinal pigment epithelial cells. Exp Eye Res 1992;55:21-28.

17 Ishida T, Ohno-Matsui K, Kaneko Y, Tobita H, Hayashi K, Shimada N, Mochizuki M: Autofluorescence of metastatic choroidal tumor. Int Ophthalmol 2009;29:309-313. 